\title{
Correlation Between Intraocular Pressure and Central Corneal Thickness in Persian Children
}

\author{
Mahmood Nejabat · Fatemeh Heidary • Mohammad Reza Talebnejad • \\ Ramin Salouti · Mohammad Hossein Nowroozzadeh • Masoumeh Masoumpour • \\ Hamideh Mahdaviazad · Zahra Tajbakhsh • Maryam Keshtkar • \\ Hossein Jamali · Mohammad Reza Khalili · Hossein Movahedan • \\ Narges Roustaei · Reza Gharebaghi
}

Received: June 23, 2016 / Published online: October 5, 2016

(C) The Author(s) 2016. This article is published with open access at Springerlink.com

\section{ABSTRACT}

Introduction: This study aimed to determine intraocular pressure (IOP) and central corneal thickness (CCT) measurements in healthy Persian children to find clinical reference values in this ethnicity. Additionally, we examined the possible relationship between these measurements.

Methods: This cross-sectional study included 262 eyes of 131 Persian primary school

Enhanced content: To view enhanced content for this article go to http://www.medengine.com/Redeem/ 8DB5F0603097FF30.

M. Nejabat · F. Heidary $(\bowtie) \cdot$ M. R. Talebnejad . R. Salouti · M. H. Nowroozzadeh · M. Masoumpour · H. Mahdaviazad · Z. Tajbakhsh · M. Keshtkar ·

H. Jamali · M. R. Khalili · H. Movahedan

R. Gharebaghi $(\bowtie)$

Department of Ophthalmology, Poostchi

Ophthalmology Research Center,

Shiraz University of Medical Sciences,

Shiraz, Iran

e-mail: drfatemehheidari@yahoo.com

R. Gharebaghi

e-mail: drgharebaghi@yahoo.com

N. Roustaei

Department of Biostatics, Faculty of Medicine,

Shiraz University of Medical Sciences, Shiraz, Iran children between 6 and 13 years of age. All eyes were healthy and had no anterior or posterior segment abnormalities, corneal disease, or evidence of glaucoma. Specular microscopy was used to measure CCT and both noncontact tonometry (NCT) and Goldmann applanation tonometer (GAT) were used to measure IOP. Correlations between IOP measurements were also examined.

Results: Mean CCT was $513.47 \pm 34.51 \mu \mathrm{m}$ in the right eye (OD) and $513.93 \pm 33.88 \mu \mathrm{m}$ in the left eye (OS). The CCT was not significantly different between older (10-13 years) and younger (6-9 years) patients. Mean IOP measured with GAT was $13.86 \pm 2.13 \mathrm{mmHg}$ OD and 13.72 $\pm 2.04 \mathrm{mmHg}$ OS and mean IOP measured with NCT was $15.26 \pm 2.38 \mathrm{mmHg}$ OD and $15.11 \pm 2.18 \mathrm{mmHg}$ OS. The IOP and CCT measured with GAT were weakly correlated (OD: $\quad r=0.141, \quad P=0.114 ; \quad$ OS: $\quad r=0.236$, $P=0.007)$. However, IOP and CCT measured with NCT (OD: $r=0.487, \quad P=0.000 ; \quad$ OS: $r=0.456, \quad P=0.000) \quad$ were moderately correlated. Our outcomes demonstrated that for $100 \mu \mathrm{m}$ increase in CCT, IOP measured with GAT and NCT increased by 0.8 and $3.3 \mathrm{mmHg}$, respectively, in OD and by 1.4 and $2.9 \mathrm{mmHg}$ in 
OS. Based on intraclass correlation coefficients, IOP measurements made with GAT and NCT were in fair agreement in OD and in good agreement in OS.

Conclusion: The IOP and CCT in healthy Persian school children (6-13 years old) were positively correlated. Our findings revealed that corneal thickness is thinner in Persian children than in most other racial groups.

Funding: This study has been funded by deputy dean in research of School of Medicine and deputy vice chancellor of Shiraz University of Medical Sciences, Shiraz, Iran.

Keywords: Central corneal thickness; Intraocular pressure; Pediatric; Persian race

\section{INTRODUCTION}

The Ocular Hypertension Treatment Study found that individuals who had lower central corneal thickness (CCT) were more probable to progress glaucoma rather than those with greater CCT values [1]. Additionally, studies revealed that thicker CCT values have an association with greater intraocular pressure (IOP) levels [2, 3]. Information highlighting the variations between ethnicities, these variables, and age [4] proves necessary to determine the relationship of CCT and IOP in children. A number of studies found a relationship between ethnicity and IOP. In addition, IOP and CCT values have proven to be different among children from various races including black and white $[5,6]$, Chinese $[7,8]$, Turkish [9], Japanese [10], Indian [11] and Malay pediatric population [12].

Unfortunately, very few studies have examined mean IOP and CCT in children living in Middle East, particularly in Iran. This study is a pioneering investigation to measure
IOP and CCT and their relationship in this specific race. This research intends to clarify mean IOP and CCT measurements for normal healthy Persian children to supply clinical reference values. Furthermore, the relationship of IOP and CCT was also examined.

\section{METHODS}

\section{Study Subjects}

All measurements were made on 6-13 years old children who attended one of four different primary schools in Shiraz, Iran selected as random sampling. All included children were Persian, which was defined as having Iranian parents for two generations and all lived in Shiraz, Iran. Children with corneal disease, clinical evidence of glaucoma, cataract, eyelid abnormalities, elevated IOP (>21 mmHg), a spherical equivalent more severe than $\pm 1.00 \mathrm{D}$, or a history of intraocular surgery were excluded from participation. Syndromic children were also excluded.

\section{Study Procedures}

Patient data documented consisted of gender, age, and race (self-reported by subjects and their parents). Snellen visual acuity measurement and a comprehensive ocular examination included complete slit lamp examination, fundoscopy, and a subjective refraction was performed. A Goldmann applanation tonometer (GAT) and noncontact pneumotonometer (NCT) were used to measure IOP. The CCT was measured by the same examiner using a specular microscope (SP-2000P, Topcon Corp., Tokyo, Japan) between 9:00 am and 2:00 pm. A single examiner made all IOP measurements. Only a 
single contact measurement has been performed for a subject therefore IOP measured using gold standard Goldmann applanation tonometer and CCT measurement has been documented with noncontact specular microscope.

\section{Data Analyses}

Using single mean formula, sample size has been calculated with the level of significance of 0.05. To assess the significance of variations in IOP and CCT between groups (e.g., between boys and girls) Student's $t$ test was used. Kruskal-Wallis test was performed to compare CCT between different age groups. Pearson correlation coefficients $(r)$ were calculated and used to find out relationships between continuous values. Additionally, intraclass correlation coefficients (ICCs) were examined for IOP measurements made with GAT and NCT to examine the agreement between measurements. Raw data analyzed using the Statistical Package for Social Science statistical software package (ver. 22.0, SPSS, Inc., Chicago, IL). To identify main data trends, descriptive analysis was done first.

\section{Compliance with Ethics Guidelines}

This research was conducted in November and December of 2015 at the Poostchi Eye Clinic of the Shiraz University of Medical Sciences, Shiraz that is located in south part of Iran. We received ethical approval from the ethical committee of the Shiraz University of Medical Sciences (No. IR.SUMS.MED.REC.1394.60). All procedures followed were in accordance with the ethical standards of the responsible committee on human experimentation (institutional and national) and with the Helsinki Declaration of 1964, as revised in 2013. Informed consent was obtained from all patients for being included in the study.

\section{RESULTS}

Totally 262 eyes of 131 healthy children were included in analyses. This included 126 eyes of 63 boys (48.1\%) and 136 eyes of 68 girls (51.9\%). Mean CCT was $513.47 \pm 34.51 \mu \mathrm{m}$ in the right eye (OD) and $513.93 \pm 33.88 \mu \mathrm{m}$ in the left eye (OS). The CCT was not significantly different between older (10-13 years) and younger (6-9 years) subjects $(P=0.980 \mathrm{OD}$, $P=0.845$ OS) or between boys and girls $(P=0.183$ OD, $P=0.189$ OS). Mean IOP measured with GAT was $13.86 \pm 2.13 \mathrm{mmHg}$ in OD and $13.72 \pm 2.04 \mathrm{mmHg}$ in the OS. Mean IOP measured with NCT was $15.26 \pm 2.38 \mathrm{mmHg}$ in the OD and $15.11 \pm 2.18 \mathrm{mmHg}$ in the OS. Measurements of IOP were not significantly different between younger and older subjects (GAT: $P=0.993 \mathrm{OD}$, $P=0.173$ OS; NCT: $P=0.487$ OD,$P=0.839$ OS) or between boys and girls (GAT: $P=0.241 \mathrm{OD}$, $P=0.320$ OS; NCT: $P=0.903$ OD, $P=0.847$ OS). IOP and CCT data comparing age and gender is summarized in Tables 1 and 2 .

Linear regression analyses disclosed a significant positive relationship between the CCT and IOP. A positive, but weak correlation was found between IOP and CCT measured with GAT (OD: $r=0.141, P=0.114$; OD: $r=0.236$, $P=0.007)$. However, IOP and CCT measured with NCT were moderately correlated (OD: $r=0.487, P=0.000$; OS: $r=0.456, P=0.000$ ). For IOP measurements with GAT, IOP increased by 0.8 and $1.4 \mathrm{mmHg}$ in $\mathrm{OD}$ and $\mathrm{OS}$, respectively, for every $100 \mu \mathrm{m}$ increase in CCT (Fig. 1). For IOP measurements with NCT, IOP increased by 3.3 and $2.9 \mathrm{mmHg}$ in the OD and OS, respectively, for every $100 \mu \mathrm{m}$ increase in 
Table 1 Mean value of IOP and CCT in different age groups

\begin{tabular}{|c|c|c|c|c|}
\hline & Age & Number & Mean & Standard deviation \\
\hline \multirow[t]{2}{*}{ GAT (OD) } & $6-9 y$ & 72 & 13.86 & 2.30 \\
\hline & $10-13 y$ & 59 & 13.86 & 1.92 \\
\hline \multirow[t]{2}{*}{ GAT (OS) } & $6-9 y$ & 72 & 13.94 & 2.30 \\
\hline & $10-13 y$ & 59 & 13.45 & 1.65 \\
\hline \multirow[t]{2}{*}{ NCT (OD) } & $6-9 y$ & 72 & 15.13 & 2.44 \\
\hline & $10-13 y$ & 59 & 15.42 & 2.32 \\
\hline \multirow[t]{2}{*}{ NCT (OS) } & $6-9 y$ & 72 & 15.07 & 2.39 \\
\hline & $10-13 y$ & 59 & 15.15 & 1.91 \\
\hline \multirow[t]{2}{*}{$\operatorname{CCT}(\mathrm{OD})$} & $6-9 y$ & 70 & 513.54 & 34.64 \\
\hline & $10-13 y$ & 59 & 513.39 & 36.44 \\
\hline \multirow[t]{2}{*}{$\mathrm{CCT}(\mathrm{OS})$} & $6-9 y$ & 69 & 513.39 & 32.55 \\
\hline & $10-13 y$ & 59 & 514.58 & 35.64 \\
\hline
\end{tabular}

$O D$ right eye, $O S$ left eye, $C C T$ central corneal thickness, IOP intraocular pressure, GAT Goldmann applanation tonometer, NCT noncontact tonometer, $y$ years

Table 2 Mean value of IOP and CCT in boys and girls

\begin{tabular}{llllr}
\hline & Gender & Number & Mean & Standard deviation \\
\hline GAT.OD & Male & 63 & 13.63 & 2.25 \\
Female & Male & 68 & 14.07 & 2.00 \\
GAT.OS & Female & 63 & 13.53 & 2.18 \\
NCT.OD & Male & 68 & 13.89 & 1.90 \\
& Female & 63 & 15.24 & 2.38 \\
NCT.OS & Male & 68 & 15.29 & 2.40 \\
& Female & 63 & 15.07 & 2.41 \\
CCT OD & Male & 68 & 15.14 & 1.96 \\
& Female & 61 & 517.75 & 30.52 \\
CCT OS & Male & 68 & 509.63 & 37.54 \\
& Female & 60 & 518.13 & 30.04
\end{tabular}

$O D$ right eye, $O S$ left eye, $C C T$ central corneal thickness, IOP intraocular pressure, GAT Goldmann applanation tonometer, $N C T$ noncontact tonometer, $y$ years 

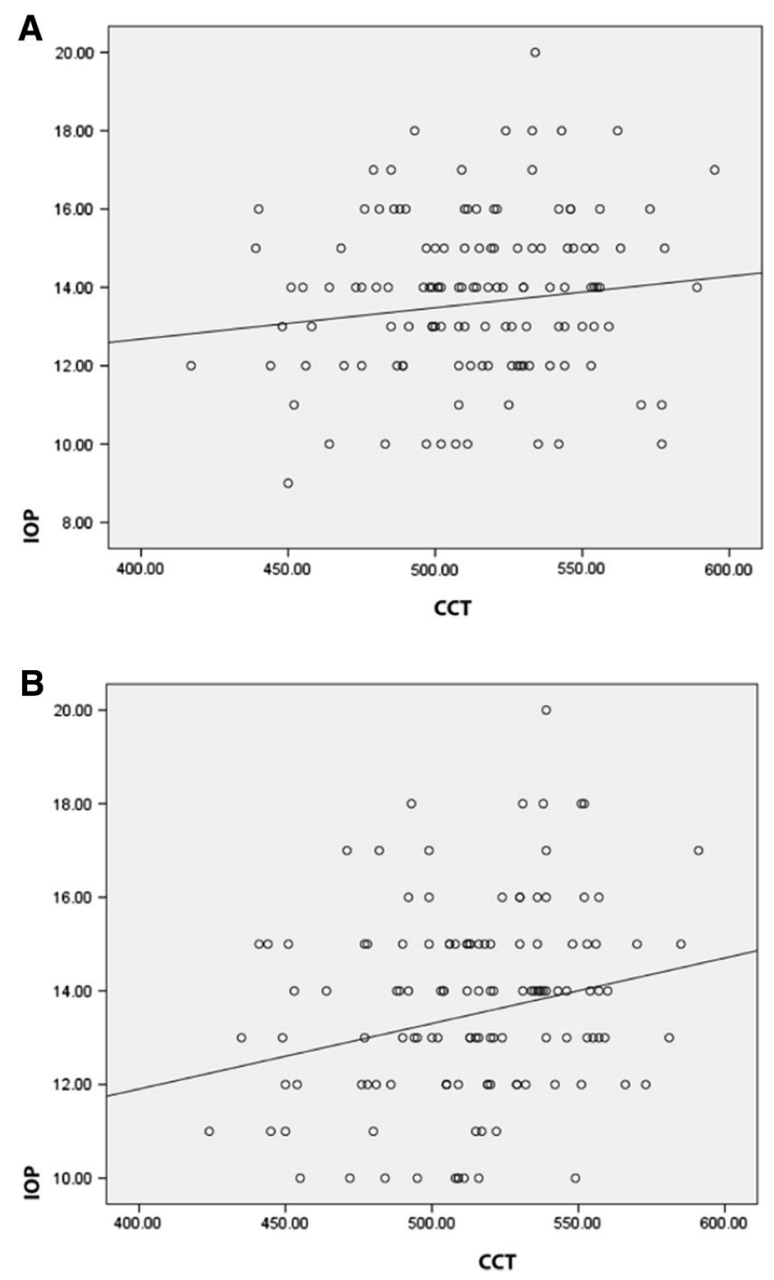

Fig. 1 Scattergrams of the CCT versus IOP measured with GAT in the OD (a) and OS (b) of Persian children that were $6-13$ years of age (OD: $n=131$ eyes, $r=0.141, P=0.114$; OS: $n=131$ eyes, $r=0.236$, $P=0.007)$. CCT central corneal thickness, IOP intraocular pressure, $G A T$ Goldmann applanation tonometer

CCT (Fig. 2). Correlation analysis revealed that the agreement between GAT and NCT IOP measurements was good in the OS (ICC $=0.603)$, but only fair in the OD $(\mathrm{ICC}=0.571)$.

\section{DISCUSSION}

This cross-sectional study of Persian school children provides IOP and CCT reference
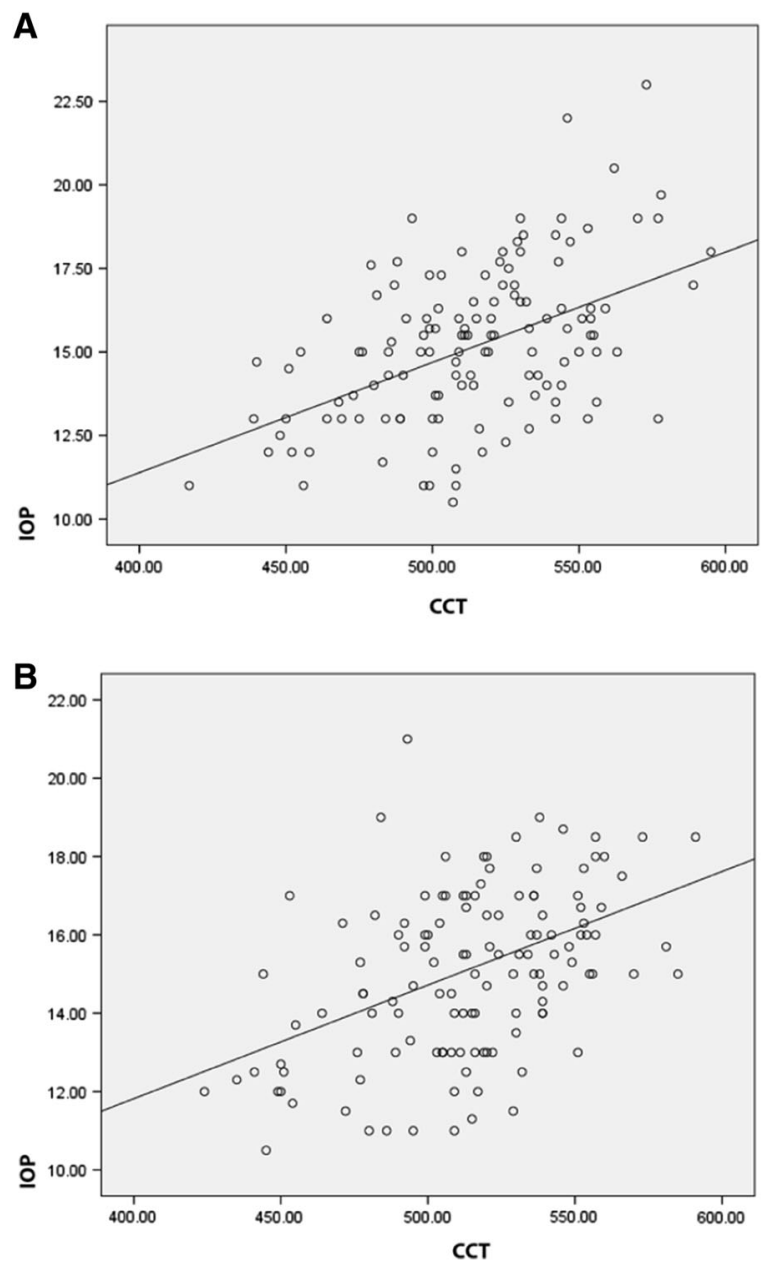

Fig. 2 Scattergrams of the CCT versus IOP measured with NCT in the OD (a) and OS (b) eyes of Persian school children that were 6-13 years of age (OD: $n=131$ eyes, $r=0.487, P=0.000$; OS: $n=131$ eyes, $r=0.456$, $P=0.000)$. CCT central corneal thickness, IOP intraocular pressure, NCT noncontact tonometer

values for this population and demonstrates that IOP is correlated with CCT. The IOP and CCT for each age group are also provided, but the relationship between CCT and age remains largely unknown. Mean CCT for all included children was $513.47 \pm 34.51 \mu \mathrm{m}$ in the OD and $513.93 \pm 33.88 \mu \mathrm{m}$ in the OS.

Our CCT measurement was lower than those reported for children of other ethnicities, including Japanese, Singaporean, Black, 
Chinese, African-American, Turkish, and Malay children [5-12]. This is important to know because a thin central cornea can indicate an underestimation of IOP and possibly impede physicians from making a glaucoma diagnosis $[12,13]$.

Ultrasound pachymetry has been considered as the current gold standard for quantifying CCT. Studies have shown specular microscopy measurements of CCT are considerably lower than ultrasound pachymetry measurements of CCT $[7,14]$. In our study, corresponding to parents' consent only a single contact measurement was taken, and therefore, the authors decided to measure IOP with gold standard Goldmann applanation tonometer and CCT measurement was documented with noncontact specular microscope. Since we used noncontact pachymetry to measure CCT, we were not able to compare current CCT findings with those of others who used ultrasound pachymetry to measure CCT. While comparing our CCT measurements with those from a similar study carried out on children from Malaysia [12] which used a similar methodology and noncontact instrumentation, this study documented thinner CCT.

We found that IOP measured with GAT increased by 0.8 and $1.2 \mathrm{mmHg}$ in OD and OS, respectively, for $100 \mu \mathrm{m}$ rise in CCT. Interestingly, this IOP increased was 3.3 and $2.9 \mathrm{mmHg}$ in OD and OS, respectively, for every $100 \mu \mathrm{m}$ rise in CCT when IOP was measured with NCT. A recent study from Northern China (The Jinan City Eye Study) [14] and Malaysia [12] presented a $3.2 \mathrm{mmHg}$ increase in IOP for every $100 \mu \mathrm{m}$ increase in CCT. Additionally, Muir et al. showed a positive association between IOP and CCT meaning that for every $100 \mu \mathrm{m}$ increase in CCT, the IOP raised by $2.2 \mathrm{mmHg}$ [6]. However, this finding is somewhat controversial because Haider et al. [4] did not find a statistically significant relationship between IOP and CCT in either African-American or White children.

The GAT is a reliable and consistent technique for measuring IOP. The IOP measurements made with NCT were in fair agreement with those made with GAT in the OD, but in good agreement with those made with GAT in OS. Shah et al. [15] revealed a significant association between PT100 air-puff and GAT measurements (Pearson's correlation $=0.715, P<0.01)$ as a recent study in Turkey showed that NCT and Tono-Pen ${ }^{\circledR}$ XL (Reichert Technologies, Depew, NY, USA) IOP measurements were both comparable to GAT, the gold standard measurement, in normotensive eyes [16].

There are a number of limitations that affected the outcomes of this study. First, the nature of our methodology as the cross-sectional study provided only one time measurement for each subgroup. Nevertheless, the absence of a relationship between age and gender in IOP and CCT does not necessarily signify that this link is nonexistent. On the other hand, younger subjects below 6 years of age, can often be uncooperative during regular ocular assessments, especially in IOP and CCT measurements under local anesthesia. The authors therefore decided to examine children of 6 years and older in this study. The authors decided to document values using noncontact pachymetry, without using general anesthesia similar to methodology of former studies in which they used noncontact pachymetry in children $[7,12,15,17]$. This may be considered as a limitation as the ultrasound pachymetry is still considered as the gold standard in the literature. Furthermore, the purpose of this research was not to correlate measurements comparing adult and children values or study 
those measurements taken over a specific period of time.

As a pioneer study in Persian children, examination of a uniform population consisting of various age groups, straightforward associations between NCT and GAT values of IOP made our outcomes significant.

It has been established that knowledge of normal ocular structures in different ethnicities may deliver a significant reference value and may contribute in the identification of diseases including glaucoma [18]. It is remarkable that the members of the same racial background who live in different countries or even different states could behave contrariwise. It is interesting to know that individuals who live in urban areas present with thicker corneas than those who live in rural areas [19].

Biomechanical characteristics of the cornea are altered by metabolic and environmental factors; particularly by UV exposure [20], therefore, environmental exposure may influence the biophysics of the eye. Therefore, further study should focus on subjects with similar racial background who live in other states with different environmental exposure as well as other countries in Middle East region. Since our analysis only focused on children with normal ocular examinations, further study is required to find the correlation between CCT and IOP in subjects with diseased corneal or pseudophakia, children who have diagnosed as congenital glaucoma or positive past medical history of glaucoma. It is our belief that longitudinal studies following the subjects from infantile to maturity would prove particularly beneficial for improving our perceptive of ocular development. A systematic review and meta-analysis on CCT and IOP values in normal children, in addition to study of the variations in corneal biometric and their relationship to other ophthalmic considerations, such as corneal curvature, axial length, and endothelial cell density, could improve our basic knowledge of the ocular health in Persian children and pediatric population who live in Middle East region.

\section{CONCLUSION}

In this study, we found that IOP and CCT in healthy Persian school children (6-13 years old) were positively correlated. Our findings revealed that corneal thickness is thinner in Persian children than in most other racial groups, however, additional studies are required to shed light on the basis of these changes as well as influence of race on these biophysical measurements.

\section{ACKNOWLEDGMENTS}

This study has been funded by deputy dean in research of School of Medicine according to study project number 93-01-01-7807 of Mrs Fatemeh Heidary dissertation and deputy vice chancellor of Shiraz University of Medical Sciences. The funders took no part in data collection, design, analysis, ruling to publish, or manuscript preparation. No funding was received for article processing charges. All named authors meet the International Committee of Medical Journal Editors (ICMJE) criteria for authorship for this manuscript, take responsibility for the integrity of the work as a whole, and have given final approval for the version to be published. We would like to appreciate very much the technical assistance of Ms. Khadijeh Nematollahi, Ms. Fatemeh Yazdanbakhsh, and Ms. Soroor Kazemi from Poostchi Eye Clinic, Shiraz University of Medical Sciences as well as Fars Province Education Organization. 
Disclosures M. Nejabat, F. Heidary, M. R. Talebnejad, R. Salouti, M. H. Nowroozzadeh, M. Masoumpour, H. Mahdaviazad, Z. Tajbakhsh, M. Keshtkar, H. Jamali, M. R. Khalili, H. Movahedan, N. Roustaei and R. Gharebaghi have nothing to disclose.

Compliance with ethics guidelines This research was conducted in November and December of 2015 at the Poostchi Eye Clinic of the Shiraz University of Medical Sciences, Shiraz that is located in south part of Iran. We received ethical approval from the ethical committee of the Shiraz University of Medical Sciences (No. IR.SUMS.MED.REC.1394.60). All procedures followed were in accordance with the ethical standards of the responsible committee on human experimentation (institutional and national) and with the Helsinki Declaration of 1964, as revised in 2013. Informed consent was obtained from all patients for being included in the study.

Open Access This article is distributed under the terms of the Creative Commons Attribution-NonCommercial 4.0 International License (http://creativecommons.org/licenses/ by-nc/4.0/), which permits any noncommercial use, distribution, and reproduction in any medium, provided you give appropriate credit to the original author(s) and the source, provide a link to the Creative Commons license, and indicate if changes were made.

\section{REFERENCES}

1. Gordon MO, Beiser JA, Brandt JD, Heuer DK, Higginbotham EJ, Johnson CA, Keltner JL, Miller JP, Parrish RK 2nd, Wilson MR, Kass MA. The ocular hypertension treatment study: baseline factors that predict the onset of primary open-angle glaucoma. Arch Ophthalmol. 2002;120(6):714-20 (Discussion 829-30).
2. Dohadwala AA, Munger R, Damji KF. Positive correlation between Tono-Pen intraocular pressure and central corneal thickness. Ophthalmology. 1998;105(10):1849-54.

3. Bhan A, Browning AC, Shah S, Hamilton R, Dave D, Dua HS. Effect of corneal thickness on intraocular pressure measurements with the pneumotonometer, Goldmann applanation tonometer, and Tono-Pen. Invest Ophthalmol Vis Sci. 2002;43(5):1389-92.

4. Haider KM, Mickler C, Oliver D, Moya FJ, Cruz OA, Davitt BV. Age and racial variation in central corneal thickness of preschool and school-aged children. J Pediatr Ophthalmol Strabismus. 2008;45(4):227-33.

5. Muir KW, Jin J, Freedman SF. Central corneal thickness and its relationship to intraocular pressure in children. Ophthalmology. 2004;111(12):2220-3.

6. Muir KW, Duncan L, Enyedi LB, Freedman SF. Central corneal thickness in children: racial differences (black vs. white) and correlation with measured intraocular pressure. J Glaucoma. 2006;15(6):520-3.

7. Wei W, Fan Z, Wang L, Li Z, Jiao W, Li Y. Correlation analysis between central corneal thickness and intraocular pressure in juveniles in Northern China: the Jinan city eye study. PLoS One. 2014;9(8):e104842.

8. Huang Y, Lin S, Ma D, Wang Z, Du Y, Lu X, Zhang M. Corneal biomechanical properties and associated factors in school-age children. Eye Sci. 2013;28(1):34-9.

9. Sakalar YB, Keklikci U, Unlu K, Alakus MF, Yildirim M, Dag U. Distribution of central corneal thickness and intraocular pressure in a large population of Turkish school children. Ophthalmic Epidemiol. 2012;19(2):83-8.

10. Hikoya A, Sato M, Tsuzuki K, Koide YM, Asaoka R, Hotta Y. Central corneal thickness in Japanese children. Jpn J Ophthalmol. 2009;53(1):7-11.

11. Sihota R1, Tuli D, Dada T, Gupta V, Sachdeva MM. Distribution and determinants of intraocular pressure in a normal pediatric population. J Pediatr Ophthalmol Strabismus. 2006;43(1):14-8 (Quiz 36-7).

12. Heidary F, Gharebaghi R, Wan Hitam WH, Naing NN, Wan-Arfah N, Shatriah I. Central corneal thickness and intraocular pressure in Malay children. PLoS One. 2011;6(10):e25208. doi:10. 1371/journal.pone.0025208 (Epub 5 Oct 2011). 
13. Shih CY, et al. Clinical significance of central corneal thickness in the management of glaucoma. Arch Ophthalmol. 2004;122(9):1270-5.

14. Bovelle R, Kaufman SC, Thompson HW, Hamano $H$. Corneal thickness measurements with the Topcon SP-2000P specular microscope and an ultrasound pachymeter. Arch Ophthalmol. 1999;117(7):868-70.

15. Shah MA, Bin Saleem K, Mehmood T. Intraocular pressure measurement: Goldmann applanation tonometer vs non contact airpuff tonometer. J Ayub Med Coll Abbottabad. 2012;24(3-4):21-4.

16. Yilmaz I, Altan C, Aygit ED, Alagoz C, Baz O, Ahmet S, Urvasizoglu S, Yasa D, Demirok A. Comparison of three methods of tonometry in normal subjects: Goldmann applanation tonometer, noncontact airpuff tonometer, and Tono-Pen XL. Clin Ophthalmol. 2014;7(8):1069-74.

17. Tong L, Saw SM, Siak JK, Gazzard G, Tan D. Corneal thickness determination and correlates in Singaporean school children. Invest Ophthalmol Vis Sci. 2004;45(11):4004-9.
18. Heidary F, Gharebaghi R, Wan Hitam WH, Shatriah I. Nerve fiber layer thickness. Ophthalmology. 2010;117(9):1861-2. doi:10.1016/j.ophtha.2010. 05.024 .

19. Zhang H, Xu L, Chen C, Jonas JB. Central corneal thickness in adult Chinese. Association with ocular and general parameters. The Beijing Eye Study. Graefes Arch Clin Exp Ophthalmol. 2008;246(4):587-92. doi:10.1007/s00417-0070760-9 (Epub 12 Jan 2008).

20. Schweitzer C, Korobelnik JF, Boniol M, Cougnard-Gregoire A, Le Goff M, Malet F, Rougier MB, Delyfer MN, Dartigues JF, Delcourt C. Associations of biomechanical properties of the cornea with environmental and metabolic factors in an elderly population: the ALIENOR study. Invest Ophthalmol Vis Sci. 2016;57(4):2003-11. doi:10.1167/iovs.1619226. 